\title{
O INSTITUTO DE ORGANIZAÇÃO RACIONAL DO TRABALHO (IDORT) COMO INSTITUIÇÃO EDUCACIONAL NAS DÉCADAS DE 1930 E 1940 NO BRASIL
}

\author{
Eraldo Leme Batista ${ }^{1}$
}

\section{RESUMO}

O Instituto de Organização Racional do Trabalho (IDORT), criado em 1931, centralizou discussões sobre o projeto industrial para o país e sobre propostas para a educação profissional, que deveria ser pensada para a formação do novo trabalhador. Como análise de fontes, trazemos as revistas do IDORT (1930-1940), documentos do Arquivo Edgard Leuenroth e do CPDOC. A partir desta pesquisa, defendemos a tese de que o IDORT tornou-se uma instituição educacional por excelência, pois formulava, divulgava e defendia teses referentes à educação e à educação profissional. $O$ que é fundamental para entendermos o período histórico e a questão da educação, pois a historiografia não considerava o IDORT uma organização educacional, mas apenas industrial, deixando aí uma lacuna, considerando que escolanovistas como Lourenço Filho, Fernando Azevedo, Noemy Silveira e professores da Escola Politécnica de São Paulo foram os fundadores do instituto e articuladores do pensamento educacional no interior da instituição, contando com o apoio de Roberto Mange, engenheiro e professor responsável pela elaboração de projetos voltados para a formação de trabalhadores. Constatamos que o IDORT foi fundamental no processo de articular o pensamento de industriais paulistas, principalmente na questão da educação.

Palavras-chave: Educação Profissional; Racionalização; Taylorismo.

\section{THE RATIONAL LABOUR ORGANIZATION INSTITUTE (IDORT) AS EDUCATIONAL INSTITUTION IN DECADES OF 1930 AND 1940 IN BRAZIL}

\begin{abstract}
The Rational Organization Institute of Labour (IDORT), created in 1931, centered discussions on the industrial project for the country and on proposals for vocational education, which should be considered for the formation of the new worker. As analysis of sources, bring the magazines IDORT (1930-1940), documents Edgard Archive Leuenroth and CPDOC. From this research, we defend the thesis that the IDORT became an educational institution par excellence, as formulated, publicized and defended theses on education and vocational education. What is important to understand the historical period and the issue of education, because the historiography did not consider the IDORT an educational organization, but only industrial, then leaving a gap, considering that New School as Lourenço Filho, Fernando Azevedo, Noemy Silveira and teachers Polytechnic School of São Paulo were the founders of the institute and organizers of educational thought within the institution, with the support of Roberto Mange, engineer and professor responsible for developing projects for the training of workers. We note that the IDORT was instrumental in the process of articulating the thought of São Paulo industrialists, mainly on the issue of education. Keywords: Professional education; Rationalization; Taylorism.
\end{abstract}




\section{INTRODUÇÃO}

Após a Primeira Guerra Mundial, com o aceleramento do processo de urbanização e o início da industrialização, a tradição da educação aristocrática já não era suficiente para atender ao processo de desenvolvimento que o país começava a vivenciar, e foi apenas nesse tempo que se começou a despertar para a educação para o trabalhador. Sendo ainda incipiente o crescimento industrial, necessitava-se de trabalhadores com preparação mínima para os postos a serem ocupados na indústria, comércio e serviços. Para tanto, a profissionalização dos trabalhadores, quando muito, era ainda oferecida nos liceus e escolas de ofícios de modo insuficiente. Os ofícios oferecidos até então eram mais artesanais que manufatureiros, distanciando-se dos propósitos industrialistas. Nesse contexto, a importação da força de trabalho especializada ficava cada vez mais difícil e fez-se necessário fomentar o ensino profissional no país.

Nesse período de transformações econômicas no modo de produção é que cresce a demanda social de educação, e o Estado expande o quadro escolar; porém, este prescreve para a escola um tipo de formação que é apenas o da instrução para o trabalho. Nesse contexto, trabalho e educação se relacionam. A organização racional do trabalho está presente na Associação Brasileira de Educação (ABE), bem como nos informam Shiroma, Moraes e Evangelista (2004, p. 19):

É evidente, por exemplo, a importância que a organização racional do trabalho encontrou no seio da ABE e como, em alguns casos, essa questão traduziu-se na valorização dos métodos de uma pedagogia que viabilizasse, no meio escolar, a realização das máximas organizadoras exigidas pelo trabalho industrial. É interessante notar como a apropriação dessa pedagogia foi funcional, no plano ideológico, para afrouxar as tensões sociais a atualizar projetos reformistas específicos. A organização racional do trabalho, entretanto, não se reduzia à adequação do trabalhador ou da trabalhadora a uma determinada ocupação industrial. Ao contrário, refletia-se também na proposta de fixação de homens e mulheres ao campo, de forma a conter o processo de crescimento urbano mediante uma distribuição "racional" da população pelas atividades rurais e urbanas.

Mesmo essa pesquisa, que teve como foco os anos de 1930 e 1940, aponta que o debate em torno da educação profissional já estava colocado no país no início do século $\mathrm{XX}$ e no decorrer dos anos veio se acentuando com a organização dos industriais no Centro das Indústrias do Estado de São Paulo (CIESP) e com a criação do Instituto de Organização Racional do Trabalho (IDORT) ${ }^{2}$, em 1931.

\section{DESENVOLVIMENTO}

Constatamos em nossa pesquisa que o interesse de empresários com a educação de jovens trabalhadores para o trabalho tornara-se cada vez mais presente no início do século XX no Brasil. O país estava aos poucos se tornando mais urbano, ocorria o processo de crescimento de cidades como São Paulo e Rio de Janeiro, além do crescimento de indústrias, no entanto os jovens trabalhadores eram, em grande parte, oriundos da zona 
rural e ainda analfabetos, tornando-se fundamental que fossem educados para aprender a ler e a escrever e para trabalhar nas indústrias. A lei n.1.184, de 3 de dezembro de 1909, já apontava para a preocupação da educação dos jovens filhos dos operários.

Esta lei determinou a criação de escolas noturnas, na capital e no interior, especificando que elas deveriam localizar-se nas proximidades das fábricas e atenderem, exclusivamente, aos meninos operários ou filhos de operários. A prioridade de instalação dessas escolas seria daquelas que tivessem acomodações oferecidas pelas empresas, e o professor seria sempre provido pelo governo estadual. A articulação com as fábricas deveria se dar, também, na definição do horário escolar (CUNHA, 2005, p. 141).

Em sua pesquisa, Cunha (2005) nos informa que o texto da lei n. 1.192, de 22 de dezembro de 1909, expressava a persistência da ideia do ensino profissional como algo destinado aos desvalidos, em consonância, aliás, com a exposição de motivos do decreto do presidente de República daquele mesmo ano.

Fica o Governo autorizado a contratar com estabelecimentos industriais, agrícolas ou beneficentes de reconhecida idoneidade, a educação profissional de menores pobres, não criminosos de ambos os sexos, que tenham mais de 11 anos de idade e que, por falta de proteção paterna ou tutelar, estiverem abandonados (CUNHA, 2005, p. 142).

Dessa maneira, no decorrer dos anos a preocupação com a formação do trabalhador foi ganhando maior importância. Em 1911, por exemplo:

[...] o decreto $\mathrm{n}$. 9.070 regulamentava as escolas de aprendizes artífices e ampliava alguns pontos do decreto n. 7.566, assinado por Nilo Peçanha. Em São Paulo, eram inauguradas as Escolas Profissionais Masculina e Feminina, que posteriormente passariam a denominar-se "Escola Técnica Getúlio Vargas" e "Escola Técnica Carlos de Campos" (SENAI, 1991, p. 114).

No ano de 1920 foi criada uma comissão com o objetivo de "examinar as escolas profissionais". Tanto a preocupação do governo com relação à educação profissional como o crescimento dos trabalhos dessa comissão. Essa mesma comissão foi transformada em 1931:

"Inspetoria do Ensino Profissional Técnico", chefiada por Francisco Montojos. Em 1934, o decreto n. 24.558 transformava a "Inspetoria do Ensino Profissional Técnico" em "Superintendência do Ensino Profissional Técnico", subordinada diretamente ao Ministério da Educação e Saúde Pública (SENAI, 1991, p. 114).

Com relação ao ensino profissional, Roberto Mange, engenheiro e professor no IDORT, já desenvolvia, desde o início dos anos de 1920, experiência voltada para a formação de trabalhadores a partir dos conhecimentos da psicotécnica para quatro importantes companhias ferroviárias, conforme nos informa Vargas (1985, p. 165). 
O debate sobre a educação profissional ${ }^{3}$, com o decorrer do tempo, vai ganhando maior importância em diversos setores da sociedade. Entendemos ainda que a defesa dos industriais para o ensino industrial se dava a partir da necessidade de se ter operários qualificados nas indústrias de ponta. Porém a questão era bem maior, pois os principais postos de trabalho eram ocupados por estrangeiros que não estavam sendo bem-vistos pelos industriais nesse período - por isso a preocupação com a formação de um trabalhador nacional.

A preocupação da burguesia com a educação profissional constituiu-se em um poderoso instrumento de controle social. Souza (2012, p. 7-8) entende que

[...] o projeto pedagógico da burguesia sempre funcionou para além dos interesses imediatos da produção, buscando as condições necessárias para que isto se cumprisse com eficácia, como um projeto de direção moral, cultural e ideológica para toda a sociedade. Nesse sentido, a ação pedagógica liberal procura legitimar a ideia de que não existem contradições entre as classes, sendo a harmonia preservada pela força de um discurso que reifica as desigualdades, tomando-as como resultado natural das diferentes formas de inserção dos sujeitos na esfera produtiva.

Ao realizar pesquisa referente aos trabalhadores ferroviários no início do século XX no Brasil, Segnini (1986, p. 88) nos informa que os principais objetivos esperados desse Centro eram: “a) Redução de custos e de tempo de formação da força de trabalho; b) Aumento de produtividade desses trabalhadores, cuja produção, em pouco tempo, compensaria as despesas efetuadas com sua aprendizagem; c) Possibilidade de maior estabilidade dos empregados na própria empresa". O projeto não era construir um novo método e técnicas de produção que beneficiariam a todos, mas sim capacitar os trabalhadores para produzirem mais, gerar mais lucro e, consequentemente, aumentar a produção por meio da mais-valia.

Em 1930, é criado o Ministério da Educação e Saúde Pública. É o primeiro período da história em que a educação é organizada à base de um sistema nacional. $\mathrm{O}$ seu primeiro ministro foi Francisco Campos, que efetivou uma série de decretos, mudanças que ficaram conhecidas como Reforma Francisco Campos. Esta abarcou, inclusive, o decreto n. 19.850, de 11 de abril de 1931, que criou o Conselho Nacional de Educação. Vale ressaltar que este, em sua origem, era composto por representações do ensino superior e secundário, não havendo nenhuma do magistério nem do ensino primário ou profissional.

Entre as principais mudanças desse período, a Reforma Francisco Campos deu origem ao ensino secundário, implantando o currículo seriado e enciclopédico. Até então, no secundário imperava o sistema de "preparatórios" e de exames parcelados para o ingresso ao superior. No nível profissionalizante, a reforma cuidou apenas do ensino comercial, com o decreto n. 20.158, de 30 de junho de 1931, que o organizava e regulamentava a profissão de contador no nível médio, e só havia a possibilidade única de acesso à educação de nível superior no curso de finanças. No entanto, não havia nenhuma articulação com o ensino secundário de então e não dava acesso ao superior de outras áreas.

Para Romanelli (2006, p. 139), a não acessibilidade do curso profissional à universidade talvez "seja uma das fortes razões que orientaram a demanda social da educação em direção ao ensino acadêmico, desprezando o ensino profissional". Essa barreira concreta e ideológica, já presente nesse período, pode ser considerada um dos 
fatores históricos que vieram a aumentar o fortalecimento do preconceito em relação aos cursos profissionalizantes.

No caso da reforma do ensino comercial, havia uma fiscalização e um controle excessivos do curso, as decisões eram muito centralizadas e tornavam muito rígida e engessada a estrutura do ensino. Na Reforma Francisco Campos, os demais ramos do ensino médio profissional, fora o comercial, ficaram marginalizados. Assim como as políticas anteriores a essa reforma, enfatizou-se apenas a organização do sistema educacional das elites.

Romanelli (2006, p. 142) argumenta que a reforma de Francisco Campos perdeu a oportunidade de investir no ensino industrial num contexto em que o país se desenvolvia para isso, "perdeu também a oportunidade de criar um clima propício à maior aceitação do ensino profissional pela demanda social de educação nascente". Para a autora, aquele tempo era propício para a estruturação de um sistema de ensino profissional, o que levaria a população a valorizar mais esse nível. Contudo, aconteceu justamente o contrário, foi no efervescer do movimento da Escola Nova (progressista) que se oficializou, na Constituição de 1937, o profissional como ensino destinado aos pobres.

Para os escolanovistas, a marcha para o "progresso" e o "desenvolvimento" do país passavam pela educação.

O Escolanovismo era o instrumento que apertava as porcas, parafusos e arruelas, e azeitava engrenagens. [...] Por fim, as marcas da modernidade apareciam na fisionomia brasileira: entre o passado e o futuro, um presente incendiado de ideias. A máquina, a fábrica, a técnica, a democracia liberal, o sufrágio esclarecido, a educação enquanto dever do Estado, a marcha do progresso, tudo foi aceito e tornado público (MONARCHA, 1990, p. 127 e 137).

No período do Estado Novo e durante o início do Governo Provisório, o país vivenciava o crescimento interno da indústria e precisava de mão de obra qualificada, porém, devido à economia de guerra, o governo enfrentava dificuldades para importar técnicos para o trabalho. Nesse contexto, acontece outra reformulação na educação, conhecida como Reforma Capanema ou Leis Orgânicas do Ensino. Essa reforma foi muito significativa e, pela primeira vez, em virtude da demanda do desenvolvimento nacional, o governo engaja-se na profissionalização em nível técnico.

A Reforma Capanema organizou o ensino técnico profissional em três áreas da economia, criando as seguintes Leis Orgânicas: ensino industrial (decreto-lei n. 4.073/42), ensino comercial (decreto-lei n. 6.141/43) e ensino agrícola (decreto-lei n. 9.613/46). Esses cursos continham dois ciclos: um fundamental, geralmente de quatro anos; e outro técnico, de três a quatro anos. Apesar da significância de se investir no nível técnico, essa reforma não conseguiu resolver os problemas sérios que surgiram nesse nível de ensino, pois havia falta de flexibilidade com o ensino secundário e restringia-se o acesso ao nível superior, uma vez que as Leis Orgânicas só permitiam tal acesso no ramo profissional correspondente.

Nas primeiras décadas do século XX, o Brasil apresentava um quadro urbano diferente e já era claro o processo de industrialização gerado pelo desenvolvimento do sistema capitalista. Devido à oferta de trabalho, houve o aumento de migrantes da zona rural para as cidades. Esse processo de expansão da indústria e do comércio foi mais 
efetivo após a Segunda Guerra Mundial. Como a maioria dos contingentes de trabalhadores não tinha formação específica, e o sistema educacional não conseguia atender em larga escala, o governo recorreu à institucionalização de agências profissionalizantes, em paralelo ao sistema oficial, a fim de preparar a mão de obra para esses serviços.

Em 1938, o governo federal elaborou, via Divisão do Ensino Industrial, um anteprojeto com o intuito de regulamentar o ensino profissional no país. O documento foi enviado para a Confederação Nacional da Indústria (CNI) e para a Federação das Indústrias do Estado de São Paulo (FIESP) para que essas instituições dessem um parecer, o que não ocorreu, pois ambas demonstraram ser contra a proposta apresentada pelo Estado. Nesse sentido é que o governo federal baixou decreto obrigando as empresas a realizarem cursos para seus trabalhadores. Com relação a essa questão, Cunha (2005c, p. 29) nos apresenta qual era a proposta apresentada pelo governo federal:

\begin{abstract}
Estipulava a criação de escolas de aprendizes industriais mantidas e dirigidas pelos sindicatos dos empregadores e pelos estabelecimentos industriais. As escolas teriam oficinas próprias destinadas à prática dos aprendizes, isto é, trabalhadores maiores de 14 e menores de 18 anos. Os cursos durariam de 8 a 16 horas semanais, em horário coincidente com o período de trabalho, remunerando-se a atividade produtiva do menor. Cada empresa industrial teria a obrigação de empregar um número de menores trabalhadores igual ou superior a $10 \%$ do efetivo total de operários. Caberia ao governo a tarefa de manter escolas de aprendizes onde os sindicatos e as indústrias não fossem capazes de fazê-lo. Os ministérios da Educação e do Trabalho fiscalizariam a aplicação do dispositivo e aplicariam sanções aos infratores.
\end{abstract}

Em sua pesquisa, Müller (2009, p. 93) nos informa que o Ministério do Trabalho, Indústria e Comércio promulgou o decreto-lei n. 6.029, em 26 de julho de 1940, estabelecendo que "[...] os cursos de formação profissional deveriam ser instalados nas próprias empresas ou nas proximidades destas, podendo ser comuns para operários de várias indústrias".

$\mathrm{Na}$ verdade, os industriais queriam dar direção e controlar essa área de formação de trabalhadores, definindo como deveriam ser os cursos ou como funcionariam as escolas, e o Estado entraria apenas com o financiamento. Nesse sentido é que Cunha (2005c, p. 30) esclarece por qual motivo os industriais eram contra esse anteprojeto: "[...] em razão das despesas com que teriam de arcar para o pagamento de salários (de aprendizes e mestres) e pelos gastos de instalação e operação de oficinas, sem contrapartida imediata de produção". Para evitar enfrentamento com o governo, a FIESP e a CNI fazem uma resistência passiva, não se pronunciando publicamente, mas também não respondendo à solicitação do governo. Esse posicionamento diante do governo federal é entendido assim por Cunha (2005c, p. 30):

[...] a situação dos industriais, de crescente dependência diante dos favores governamentais, em termos fiscais, alfandegários e creditícios, não encorajava uma resistência ativa ao anteprojeto. Assim, a CNI 
optou pela resistência passiva, simplesmente não respondendo à consulta ministerial.

Além desse embate entre industriais e governo, ocorria também, entre o Ministério do Trabalho e Ministério da Educação, uma disputa a respeito de qual ministério seria responsável pela implementação e gestão da educação profissional no país. Nessa disputa, venceram os interesses do Ministério do Trabalho, Indústria e Comércio, deixando Capanema contrariado com a decisão de Vargas. Müller (2009, p. 138) entende que o que estava em disputa eram interesses de frações de classe no interior do governo:

\begin{abstract}
A disputa dos ministros pode ser entendida como um embate entre frações do próprio capital tentando se acomodar, ou seja, uma "queda de braço" para verificar quem mantinha a hegemonia para dominar o grupo adversário. No caso, quem estava mais próximo ao Estado, conquistou essa hegemonia, sendo que o embate terminou pelo arbítrio do próprio presidente Vargas, que optou pelo Ministério do Trabalho, Indústria e Comércio para negociar com os empresários. Esses acabaram aceitando as normas impostas pelo referido Decreto, assumindo, sem outra opção, os custos financeiros pela formação profissional de seus operários. Assim, em 26 de julho de 1940 foi assinado o Decreto 6.029/40 que regulamentava a instalação e funcionamento de cursos profissionalizantes previstos no Decreto $1.238 / 39$, porém com algumas mudanças que poderiam orientar as indústrias no cumprimento do disposto. Definia-se ali, ainda, a função de aprendiz como trabalhador ligado à indústria, mas com carga horária diária e salários diferenciados.
\end{abstract}

Em 1942, contando dessa vez com a participação dos industriais, é criado em convênio com a CNI, por meio do decreto-lei n. 4.048 de 1942, o Serviço Nacional de Aprendizagem Industrial (SENAI) e, quatro anos depois, o Serviço Nacional de Aprendizagem Comercial (SENAC), pelo decreto-lei n. 8.621 de 1946, dirigido e organizado pela Confederação Nacional do Comércio (CNC). As duas instituições foram criadas para atender à demanda de qualificação para o trabalho em todos os níveis de profissionalização. Atualmente são responsáveis pela maior rede de escolas de educação profissional no Brasil.

A criação desses sistemas de educação profissional paralelos teve o intuito de capacitar, de forma rápida, um número maior de pessoas para os setores de produção imediatos, porém tal política não foi suficiente para amenizar os problemas educacionais no país. Romanelli (2006) argumenta que, ao se tomar essa medida, o governo descuidou de manter um sistema único de escola, prevalecendo o dual de ensino, no qual as camadas médias e superiores procuravam o ensino secundário e superior enquanto os populares recorriam às escolas de nível primário e profissional.

Assim, ainda considerando as iniciativas importantes para a educação profissional nas décadas de 1930 e 1940, como as reformas educativas supracitadas, podemos afirmar que a dualidade na educação profissional, constatada desde o período colonial, prevaleceu. Além das reformas do ensino, outros fatos históricos desse período são importantes para que se compreenda a reorganização da educação profissional no Brasil, como é o caso do IDORT, retratado a seguir. 


\section{O IDORT COMO INSTITUIÇÃO EDUCACIONAL}

Destacamos agora o papel estratégico e fundamental de Roberto Mange para desenvolver as experiências racionais na formação dos trabalhadores. Não se trata de um intelectual qualquer, mas de uma liderança do movimento pela administração científica do trabalho, portanto taylorizado, que tinha trânsito com diversos representantes da burguesia industrial brasileira e do pensamento educacional. Mange ${ }^{4}$ era amigo de Lourenço Filho ${ }^{5}$, de Fernando Azevedo e de Anísio Teixeira, os organizadores do Manifesto dos Pioneiros ${ }^{6}$. Lourenço Filho desenvolve experiências de educação profissional com Mange. Azevedo convida-o para participar do documento conhecido como Inquérito Educacional de Fernando de Azevedo, realizado em 1926.

Torna-se fundamental destacar essa relação entre os principais articuladores da Escola Nova com Mange e o IDORT, possibilitando, assim, entendermos os pressupostos inerentes na pedagogia escolanovista, ou seja, a defesa de uma utopia racional, procurando, com isso, negar:

[...] a história enquanto história da luta de classes, produzindo um imaginário em que o movimento progressivo da história era decorrência do choque contínuo entre o moderno e o arcaico, o racional e o irracional, o novo e o velho, em síntese: entre Tradição e Modernidade. Recolocada sob novas bases: "classes laboriosas" e "classes dirigentes", a divisão não representava o exercício de poder de uma classe sobre outra, refletia apenas a organização científica do mundo do trabalho e da sociedade (MONARCHA, 1990, p. 76).

Ao apresentar Mange como um dos inquiridos que iria trabalhar o ensino profissionalizante, Azevedo tece muitos elogios à atuação do amigo:

Para quem conhece de perto ou apenas visitou a Escola Profissional Mecânica, do Liceu de Artes e Ofícios, o depoimento de hoje, sobre este ramo de ensino, tem duplo interesse. Já bastava para revesti-lo de autoridade, ser de um especialista a mão que o traçou. Mas ele não reflete somente o pensamento do engenheiro mecânico, que tem prestado à Escola Politécnica de São Paulo, no exercício do magistério, o concurso de sua matéria, dobrado prestígio é o fato de concorrerem ao Dr. Roberto Mange o saber técnico de um especialista em máquinas e o espírito de organização, positivo e luminoso, a que se deve, em São Paulo, a mais bela tentativa nos domínios do ensino profissional mecânico. Embora de iniciativa privada e fundação recente, a Escola Profissional Mecânica tende, de fato, a transformar-se em paradigma das escolas desse gênero. Não é a obra de improvisação impelida, sem objetivo claro, ao capricho das circunstâncias. É empreendimento que obedece, nos menores detalhes, a um plano de ideias seguras e precisas. Tudo o que ali se realiza, atinge, por isto, resultados certos como os que coroaram a execução, pela primeira vez entre nós, dos métodos de seleção profissional baseados na psicologia e fisiologia aplicadas ao trabalho (AZEVEDO, 1957, p. 149). 
Mesmo sendo professor de sistema privado de ensino técnico, Mange foi convidado para falar sobre educação profissional no inquérito de Azevedo, tendo em conta o seu conhecimento na área. A relação entre eles não era somente de amizade, mas de admiração, sendo que Azevedo não economizava palavras para elogiar o engenheiro.

Ao descrever os empreendimentos de Mange, Azevedo não economiza elogios pessoais tais como: "notória capacidade", "dobrado prestígio"; e também com relação a seus empreendimentos: "espírito de organização, positivo e luminoso", "a mais bela tentativa nos domínios do ensino profissional mecânico", etc. Além disso, antevê as repercussões das inovações pedagógicas trazidas por Mange, afirmando que o curso se tornaria um paradigma para escolas desse gênero (ZUCCHI, 2007, p. 77).

O prestígio de Mange com os educadores escolanovistas e industriais era tanto que, em vez de se ouvir o diretor da mais importante escola pública profissional de São Paulo, Aprígio Gonzaga, quem é convidado e participa do inquérito é Mange. Gonzaga tinha uma visão mais independente, era mais crítico em relação à formação dos trabalhadores, enquanto Mange defendia e buscava implementar o projeto definido pela elite industrial que estava ligada ao IDORT.

Foi a visão de Mange sobre treinamento profissional que se firmou como a tendência predominante no Brasil. [...] Assim, não é de se surpreender que Fernando Azevedo tenha entrevistado Mange e não Gonzaga (que, afinal de contas, era o diretor da mais importante escola pública profissional de São Paulo) em sua pesquisa. Foi a entusiástica campanha de Roberto Mange pela organização racional que atraiu os educadores brasileiros mais inovadores, que procuravam criar para o país um sistema educacional perfeitamente moderno (WEINSTEIN, 2000, p. 56).

O IDORT, entidade criada pelos empresários paulistas, foi fundamental para a discussão e reorganização do ensino profissional no Brasil, mas foi na década de 1940 que os industriais conseguiram, mesmo não concordando com a centralização da discussão nas mãos do Estado, criar uma importante escola de formação dos trabalhadores. Foi no período do Estado Novo (1937-1945) que os industriais conseguiram regulamentar as propostas de ensino profissional no Brasil, a partir da Reforma Capanema (1942), conhecida também como Leis Orgânicas do Ensino, como já citado anteriormente. Essa reforma estruturou o ensino profissional, reformulou o ensino comercial e criou o SENAI.

Os intelectuais orgânicos da burguesia industrial tanto eram do setor industrial, quanto educacional, sendo que diversos educadores contribuíram com a fundação do IDORT, como Lourenço Filho, Fernando Azevedo, Anísio Teixeira, Noemy Silveira, além de outros professores da Universidade de São Paulo (USP). Entendemos que esses intelectuais eram afinados com o projeto da burguesia industrial, portanto não foram cooptados, pois suas ideias eram as mesmas dessa classe, participando ativamente das suas iniciativas. Mange era um intelectual burguês, assim como Lourenço Filho e Azevedo, com suas teses educacionais no campo do liberalismo, ou seja, eles acreditavam no que faziam, eram homens de seu tempo.

Expomos a seguir a visão do IDORT sobre a preparação do trabalhador, ressaltando que o projeto do instituto é pensado para o indivíduo desde a mais tenra idade. O objetivo era o de "inculcar" na criança, a partir da escola, quais seriam suas únicas possibilidades de 
sobrevivência na sociedade capitalista. A elas não restava nada mais além de escolher uma das profissões do "cardápio" e com ela tentar a prosperidade, segundo os princípios da ética do trabalho. O serviço de orientação deveria também se preocupar com o perfil psicológico dos futuros operários, para que estes fizessem a escolha certa de profissão. Os inadequados, num longo processo de aprendizagem, poderiam se adequar ao leque profissional ou não. Isso fica explícito na Revista IDORT (1932, n. 2, p. 4): “a cooperação com as escolas para tornar conhecidas as profissões normais da cidade e do pais; levantamento do cadastro e elaboração do perfil psicológico das diferentes profissões; trabalhos para guiar candidatos na escolha certa".

Ainda conforme a Revista IDORT (1932, n. 2, p. 4):

Análise do trabalho nas várias profissões para verificação das aptidões básicas de cada uma, seleção por meio de testes, de candidatos a determinadas profissões, tais como: aprendizes e operários industriais, condutores de veículos, telefonistas, telegrafistas, ferroviários, agentes de segurança, aviadores etc.; colaboração na organização de cursos de educação profissional, tendo em vista o desenvolvimento racional das aptidões na base psicotécnica, bem como a aquisição metódica de conhecimentos tecnoprofissionais; verificação da eficiência de provas e métodos psicotécnicos; determinados padrões profissionais (valores médios) em nosso meio.

Os industriais procuravam disseminar suas ideias por meio da Revista IDORT, elaboradas por seus intelectuais orgânicos, desqualificando os discursos operários, a cultura popular, visando criar outra sociedade, um homem passivo, transformando o operário em um ser dócil, disciplinado, colaborador, patriota e, acima de tudo, que não compactuasse com as ideias "estranhas" dos trabalhadores estrangeiros.

Essa concepção figura em toda publicação da revista do instituto, pois os industriais tinham estratégia bem definida de difusão do taylorismo, considerando que, de um lado, propunham e "preocupavam-se" com a capacitação e formação da classe trabalhadora, de outro buscavam formar quadros para gerenciarem as empresas e difundirem as ideias de organização racional do trabalho, conforme muito bem nos informa Segnini (1986, p. 88): "[...] concomitantemente, a Escola Politécnica de São Paulo, que procurava formar dirigentes para assumir o controle nas empresas taylorizadas, introduzia no currículo de curso de engenharia a organização racional do trabalho".

\section{CONCLUSÃO}

A partir dos estudos realizados, compreendemos que os industriais do referido período tinham como estratégia formar profissionalmente os trabalhadores brasileiros para trabalharem na indústria em crescimento, além de ser um mecanismo para fragilizar e fragmentar a organização dos trabalhadores, que tinham até aquele momento um perfil de trabalhadores críticos, muitos deles europeus ou descendentes de europeus e vinculados a grupos políticos como os anarquistas e comunistas. Um projeto que visava retirar esses trabalhadores críticos do chão da fábrica, pois estes, em sua maioria, eram "contestadores" e podiam criar "problemas" para o projeto nacionalista de industrialização do país. O projeto de investimento da formação dos trabalhadores dava-se também em decorrência da escassa força de trabalho especializada para trabalhar com novos equipamentos que estavam sendo implantados na indústria em crescimento no período. 
Constatamos que nas décadas de 1930 e 1940, o IDORT foi uma instituição educacional de relevada importância, desenvolvendo projetos pedagógicos para a educação profissional no país, um projeto bem definido e coordenado pelo engenheiro Roberto Mange, originando, a partir dessas experiências, na fundação do SENAI, em 1942.

\section{REFERÊNCIAS}

AZEVEDO, F. A educação na encruzilhada. São Paulo: Melhoramentos, 1957.

BRYAN, N. A. P. Educação, processo de trabalho, desenvolvimento econômico. Campinas: Alínea, 2008.

CUNHA, L. A. O ensino de ofícios artesanais e manufatureiros no Brasil escravocrata. São Paulo: UNESP, 2005a. $2005 b$.

O ensino de ofícios nos primórdios da industrialização. São Paulo: UNESP,

O ensino industrial na irradiação do industrialismo. São Paulo: UNESP, 2005c.

REVISTA IDORT. Pela cooperação: a guerra econômica e o Instituto de Organização Racional do Trabalho de São Paulo, n. 2, p. 1-2-, fev. 1932.

MÜLLER, M. T. A lousa e o torno: a escola SENAI Roberto Mange de Campinas. Tese (Doutorado em Educação) - Faculdade de Educação, UNICAMP, Campinas, 2009.

MONARCHA, C. A reinvenção da cidade e da multidão. Dimensões da modernidade brasileira: a Escola Nova. São Paulo: Cortez; Autores Associados, 1990.

PICHELI, V. O IDORT enquanto proposta educacional no contexto de formação da hegemonia burguesa no Brasil (1930-1944). Tese (Doutorado em Educação) - Faculdade de Educação, UNICAMP, Campinas, 1997.

ROMANELLI, O. O. História da educação no Brasil. Rio de Janeiro: Vozes, 2006.

SEGNINI, L. R. P. Taylorismo: uma análise crítica. In: BRUNO, L. Organização, trabalho e tecnologia. São Paulo: Atlas, 1986.

SENAI. De homens e máquinas: Roberto Mange e a formação profissional. São Paulo, SENAI, 1991.

SENAI. O giz e a graxa: meio século de educação para o trabalho. Projeto Memória SENAI-SP. São Paulo: SENAI, 1992.

SHIROMA, E. O.; MORAES, M. C. M; EVANGELISTA, O. Política educacional. Rio de Janeiro: Lamparina, 2004.

SOUZA, E. G. de. Relação trabalho-educação e questão social no Brasil: uma leitura do pensamento pedagógico da Confederação Nacional da Indústria - CNI (1930-2000). Tese (Doutorado em Educação) - Faculdade de Educação, UNICAMP, Campinas, 2012.

ZUCCHI, B. B. O programa e os métodos de treinamento profissional do curso de ferroviários da Companhia Sorocabana (São Paulo, Década de 1930). Dissertação (Mestrado em Educação) - Pontíficia Universidade Católica de São Paulo, São Paulo, 2007. 


\section{WEINSTEIN, B. (Re)formação da classe trabalhadora no Brasil, 1920-1964. São Paulo: Cortez; CDAPH-IFAN, 2000.}

\footnotetext{
${ }^{1}$ Doutor em Educação pela Unicamp. Professor do colegiado de pedagogia da UNIOESTE, Campus de Cascavel, PR. Pós-doutorando em educação pela UNIOESTE, com bolsa pesquisa Capes.

${ }^{2}$ O IDORT tinha como um de seus objetivos "[...] estabelecer um novo paradigma para nortear as relações entre as classes sociais. Ao invés do conflito, das lutas de classes tão evidentes naquele período histórico, buscava-se a conciliação entre as classes, fator igualmente fundamental para a aceleração do desenvolvimento industrial" (PICHELLI, 1997, p. 15-16, grifos nossos).
}

${ }^{3}$ A principal referência do IDORT com relação à educação profissional foi Roberto Mange: "o introdutor dos métodos tayloristas nas instituições de formação profissional e na organização do trabalho no Brasil [...] nasceu em 1885, na cidade suíça de La Tour-de-Peilz. Filho de um Diplomata, fez seus estudos na Alemanha [...] Contratado em 1903, com a idade de 28 anos, para lecionar desenho de máquinas na Escola Politécnica de São Paulo, influenciou várias gerações de engenheiros que, após passarem por suas mãos, ocuparam altas cargos na burocracia estatal e nas empresas públicas" (BRYAN, 2008, p. 25).

${ }^{4}$ Roberto Mange, Lourenço Filho e Fernando Azevedo eram amigos e membros fundadores do IDORT.

${ }^{5}$ Esse educador teve papel fundamental no movimento escolanovista e também como responsável pela reforma do ensino ocorrida no estado do Ceará. Foi um dos fundadores do IDORT e tradutor de importantes psicólogos do trabalho, como Henri Pieron, da Universidade de Paris, e Léon Walther, do Instituto Rousseau da Universidade de Genebra. Também foi importante divulgador das teses tayloristas no Brasil e publicou respeitáveis obras sobre a organização e psicologia aplicada ao trabalho.

${ }^{6}$ Mange era reconhecido por sua participação em instituições de ensino profissionalizante, acompanhou de perto os debates anteriores à redação do Manifesto dos Pioneiros, porém "seu nome não figura entre os signatários porque, nessa época, ele ainda não havia optado pela cidadania brasileira, estando, portanto, impedido de firmar documentos de natureza política (SENAI, 1991, p. 90).

Recebido: junho-15 Aprovado: julho-15 